\title{
Reliability of molecular host-identification methods for ticks: an experimental in vitro study with Ixodes ricinus
}

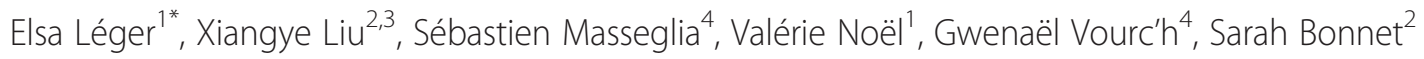
and Karen D. McCoy ${ }^{1}$

\begin{abstract}
Background: Reliable information on host use by arthropod vectors is required to study pathogen transmission ecology and to predict disease risk. Direct observation of host use is often difficult or impossible and indirect methods are therefore necessary. However, the reliability of currently available methods to identify the last host of blood-feeding arthropods has not been evaluated, and may be particularly problematic for ticks because host blood has been digested at capture. Biases in host detection may lead to erroneous conclusions on both vector ecology and pathogen circulation.
\end{abstract}

Methods: Here, we experimentally tested for biases in host detection using the generalist three-host tick Ixodes ricinus as a model system. We fed ticks using an artificial feeding system and amplified blood meal traces post-moult (i.e., in the succeeding unfed life stage) via both a quantitative real-time polymerase chain reaction assay and a reverse line blotting method. We then experimentally tested for three types of biases in host detection: 1) time post-moult, 2) tick life stage and 3) host type (non-nucleated mammal blood versus nucleated avian blood), and compared these biases between the two molecular methods.

Results: Our results show that all three factors can influence host detection in ticks but not necessarily in the expected way. Although host detection rates decreased with time post-moult, mammal blood tended to be more readily detected than bird blood. Tick life stage was also an important factor; detection was higher in nymphs than in adults and, in some cases, remnants from both larval and nymphal blood meals could be detected in the adult stage. These biases were similar for the two detection techniques.

Conclusions: We show that different factors associated with questing ticks may influence our ability to correctly infer previous host use and that these factors may bias inferences from field-based studies. As these biases may be common to other vector-borne disease systems, their implications for our understanding of vector ecology and disease transmission require more explicit consideration.

Keywords: Host identification, Hematophagous arthropods, Ixodidae, Molecular methods, Detection biases, Vector-borne diseases

\footnotetext{
* Correspondence: leger.elsa@gmail.com

${ }^{1}$ MIVEGEC (UMR UM2-UM1-CNRS 5290, UR IRD 224), Centre IRD, 911 avenue

Agropolis, BP 64501, 34394 Montpellier, Cedex 5, France

Full list of author information is available at the end of the article
} 


\section{Background}

Vector-borne diseases are often maintained in complex transmission cycles that include numerous potential reservoir host species. To understand vector ecology and pathogen circulation, and to reliably predict disease risk, the contribution of different host types to local vector-host-pathogen interaction networks needs to be established [1-4]. Molecular techniques, such as groupspecific polymerase chain reaction (PCR), restriction fragment length polymorphisms (RFLP), reverse lineblot hybridisation (RLBH) and DNA barcoding, are currently employed to identify host use in a wide range of blood-feeding arthropods (e.g., mosquitoes, ticks, reduviid bugs, sandflies, fleas, tsetse flies, biting midges) without the need to directly collect the vector on the host $[5,6]$. The overall success in host identification is known to vary across techniques and vector systems (e.g., [7-14] and see [5, 6] for reviews), but the representativeness of the detected hosts in terms of correctly determining the way the natural systems function has not been evaluated to date. Undetected biases could result in an erroneous perception of local host use and, thus, of pathogen circulation. In the present study, we conducted a controlled experiment to identify and quantify potential biases in host detection in ticks using the well-known generalist tick Ixodes ricinus (Acari, Ixodidae) as a model system.

I. ricinus is a three-host tick, with a single compulsory blood meal during each of its three active stages: larva, nymph and adult (except for adult male). The complete cycle of this tick is rather long, taking between two and six years to complete [15] with a relatively long interval between blood meals. I. ricinus is the most widespread and abundant tick in western Europe, parasitising a vast range of terrestrial vertebrates including mammals, birds, and reptiles, and transmitting a wide variety of viral, bacterial and parasitic diseases of medical and veterinary importance [16], including Lyme borreliosis, the most prevalent vector-borne zoonosis in both Europe and North America [17].

Potential biases in host detection/identification could arise through several factors in species such as I. ricinus. First, due to their large host range, variation in detection can occur because certain host types may be more easily detected than others due to differences in the amount of ingested DNA (e.g., nucleated versus non-nucleated host red blood cells) $[5,8,18,19]$ or to the presence of amplification inhibitors [20-22]. Detection may also vary with the tick life stage. Indeed, hard ticks are frequently sampled off-host during the questing phase, when the blood meal from the preceding life stage has been completely assimulated. As blood digestion is intracellular, with digestive cells of the midgut phagocytising the blood using specialised structures called endosomes, small amounts of undigested blood from the previous blood meal may be stored $[23,24]$. This allows DNA-based detection of vertebrate blood meals for a greater period of time than for other hematophagous arthropods, but also means that whereas questing nymphal ticks should only carry host DNA from the larval blood meal, questing adult ticks may carry trace DNA from both larval and nymphal blood meals [8, 19, 25, 26]. Finally, previous studies have also suggested that the time since the last blood meal is an important factor to consider in the ability to identify host use because host DNA remnants may continue to degrade over time [12, 18, 26, 27].

Using a full cross-feeding design (Fig. 1) combined with an artificial feeding system [28-30] and two different molecular methods for amplifying host blood meal traces (quantitative real-time polymerase chain reaction (qPCR) and reverse line blot hybridisation (RLBH) methods), we experimentally tested for biases in host detection in I. ricinus. In terms of host type, we used two blood sources (bird and mammal) and hypothesized that avian blood would have higher overall detection rates and thresholds than mammalian blood due to differences in the amount of DNA ingested by feeding ticks; birds have nucleated red-blood cells whereas mammals do not. Although host DNA is also present in white blood cells, lysed subcutaneous tissue and skin cells, differences in the quantity of DNA in red blood cells (nucleated versus non-nucleated) can be substantial (see Methods) and we therefore focused on this aspect. We also predicted that host detection would be higher in adult ticks than in nymphal ticks due to larger blood meal size in the previous life stages. Finally, we expected that that detection would decrease with time post-moult due to DNA degradation in the midgut. We discuss the significance of our results for understanding the reliability of host molecular detection methods and the consequences of potential biases for our understanding of vector-borne diseases.

\section{Methods}

Ticks

All experiments were performed with I. ricinus ticks from a pathogen-free laboratory colony, reared at $22{ }^{\circ} \mathrm{C}$ with $80-90 \%$ relative humidity and with a $12 \mathrm{~h}$ light/dark cycle [28-30]. This colony has been maintained over several generations in the CRBM (Centre de Recherches Biomédicales) in Maisons-Alfort, but is regularly supplemented with adult ticks from the wild. Field collected females are engorged on rabbits and maintained in standard laboratory conditions until egg-laying. After egg-laying is complete, the DNA from these females are extracted and tested for the presence of pathogens. Only progeny from uninfected mothers are added to the colony [29]. Ticks of the colony are 


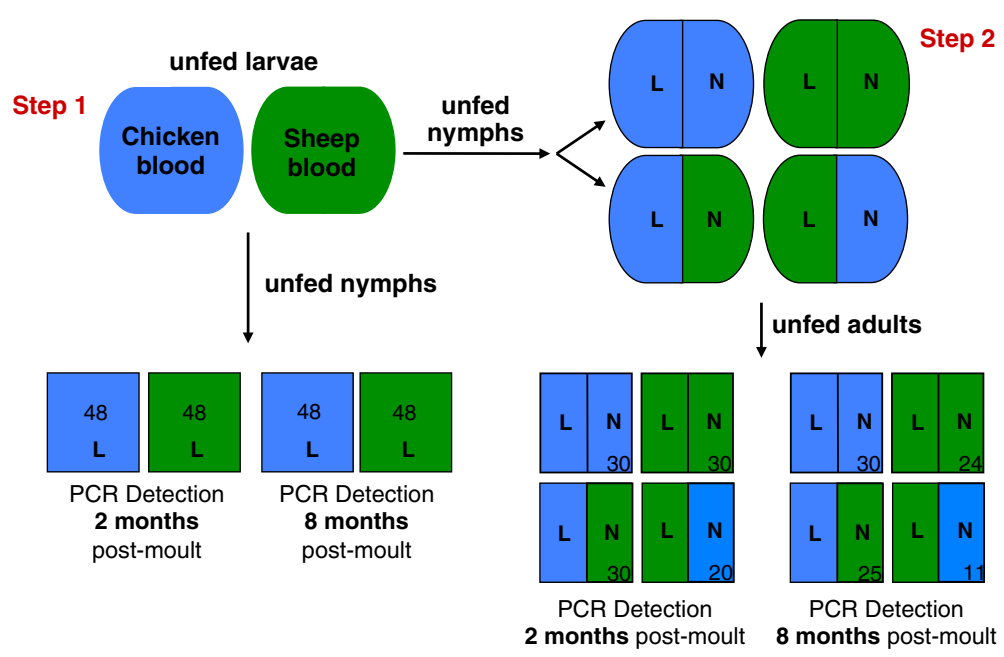

Fig. 1 Experimental design for testing host detection probabilities in ticks. In step 1, unfed larvae were fed on sheep or chicken blood. Engorged larvae were then maintained under standard laboratory conditions until the moult. One half of the newly moulted nymphs were kept for host detection analysis. In step 2, the other half of unfed nymphs from step 1 were again fed using the artificial feeding system with four treatment types: nymphs fed as larvae on one host blood type were either fed again on the same blood type (blood meal treatments "sheep-sheep" and "chicken-chicken") or on a different blood type (blood meal treatments "sheep-chicken" and "chicken-sheep"). Fully-engorged nymphs that detached from the membrane were kept under standard laboratory conditions until the moult into the adult life stage. The sample sizes of ticks analysed for host use are indicated for each treatment. Blue represents chicken blood meal and green sheep blood meal. $\mathrm{L}=$ larval blood meal, $>\mathrm{N}=$ nymphal blood meal

typically fed artificially on sheep blood in the larval stage and directly on laboratory rabbits in the nymphal and adult life stages.

\section{Experimental design}

In order to test for biases using indirect host detection methods, our experimental design included two major feeding steps, one at the larval stage and one at the succeeding nymphal stage, and four experimental groups according to the source of host blood (bird/bird, mam$\mathrm{mal} / \mathrm{mammal}$, bird/mammal, mammal/bird). At each step, a random sample of unfed ticks from each group was tested for host DNA traces at both two and eight months post-moult to determine the effect of time on detection. The details of the experimental design and sample sizes are presented in Fig. 1.

\section{Tick engorgement, maintenance and DNA extraction}

The artificial feeding system employed has been previously described $[28,30]$ and we therefore only provide supplementary information here. Two types of skin membranes were used on the artificial feeders, either gerbil (Meriones unguiculatus) or rabbit (Oryctolagus cuniculus). The blood supply for the artificial feeders came from two sources: sheep (Ovis aries) blood purchased from BioMerieux Laboratories (France), and chicken (Gallus gallus) blood taken directly from living animals maintained on site. As expected, substantial differences in the amount of DNA present in each blood meal source were apparent: $1.3 \mathrm{mg} \mathrm{DNA} / \mathrm{g}$ of chicken blood and $0.003 \mathrm{mg}$ DNA/g of sheep blood, quantified using a Tecan NanoQuant Plate Infinite 200. After moulting, unfed nymphal and adult ticks from the different experimental groups were maintained separately under the standard laboratory conditions mentioned above. After the planned post-moult period, ticks were placed directly at $-80{ }^{\circ} \mathrm{C}$ until DNA extraction.

Prior to DNA extraction, ticks were washed twice in distilled water to eliminate impurities. The whole body of the tick was then ground using a sterile piston and scissors. DNA was extracted using the DNeasy ${ }^{\circ}$ Blood \& Tissue Kit (QIAGEN, Hilden, Germany) following manufacturer's instructions. DNA extracts were then stored at $-20{ }^{\circ} \mathrm{C}$.

\section{Real-time qPCR assay}

We developed a quantitative real-time polymerase chain reaction (qPCR) assay based on the amplification of a partial fragment of the $12 \mathrm{~S}$ gene in an attempt to simultaneously detect and quantify host DNA. Sheep and chicken $12 \mathrm{~S}$ rDNA sequences were downloaded from GenBank [AF010406; AY235571, AP003580.1] and aligned using BioEdit [31]. Specific forward and reverse primers were designed using Primer3Plus [32] (Table 1). qPCR assays were performed using a LightCycler ${ }^{\circ} 480$ PCR instrument (Roche Diagnostics, Mannheim, Germany). Both DNA concentration and the amplification program used 
Table 1 Primer sequences used for the qPCR assay and probes and PNA sequences used for the Reverse line blotting method in this study

\begin{tabular}{llll}
\hline Name & Target organism & Position & Sequence \\
\hline 12Sov & Sheep (Ovis aries) & Forward & CCAGCCTTCCTGTTAACTTCAATAGACT \\
& & Reverse & TTAGTCCTGTGTGATTCGAAGGGCG \\
$12 \mathrm{Sgg}$ & Chicken (Gallus gallus) & Forward & CTCGCTAATAAGACAGGTCAAGGTA \\
& & Reverse & TAGGGGGTATGATCTCACTTACTG \\
Chicken probe & - & Amino-ACCTCCCATCACACATGT \\
Sheep probe & Chicken (Gallus gallus) & Amino-AAATAATTATAAAAACAAAATTATTC \\
PNA clamp & Sheep (Ovis aries) & Heverse & H-GTGTTCTGGCGAGCAGTT-NH2 \\
\hline
\end{tabular}

were optimised for the DNA templates. Reactions were performed in $10 \mu \mathrm{L}$ reaction mixtures containing $2 \mathrm{x}$ LightCycler ${ }^{\circ} 480 \mathrm{SYBR}^{\circ}$ Green I Master, $10 \mu \mathrm{M}$ of each primer and $1 \mu \mathrm{L}$ of tick DNA extract (diluted to approximately $10 \mathrm{ng} / \mu \mathrm{L}$ ). The amplification program consisted of an initial $10 \mathrm{~min}$ denaturation step at $95^{\circ} \mathrm{C}$, followed by 50 cycles with $10 \mathrm{~s}$ of denaturation at $95^{\circ} \mathrm{C}$ and $1 \mathrm{~min}$ of annealing and extension at $64{ }^{\circ} \mathrm{C}$. Fluorescence was measured at the end of each extension step. After amplification, a melting curve was acquired by heating the product at $20{ }^{\circ} \mathrm{C} / \mathrm{s}$ to $95{ }^{\circ} \mathrm{C}$, cooling it at $20{ }^{\circ} \mathrm{C} / \mathrm{s}$ to $60{ }^{\circ} \mathrm{C}$, keeping it at $60{ }^{\circ} \mathrm{C}$ for $20 \mathrm{~s}$, and then slowly reheating it at $0.1{ }^{\circ} \mathrm{C} / \mathrm{s}$ to $95{ }^{\circ} \mathrm{C}$. During this stage, fluorescence was measured through the slow reheating phase.

PCR efficiency was measured for each target by generating standard curves with DNA isolated from the whole blood of each host type, diluted 10 fold, 4 times, from a starting concentration of $5 \mathrm{ng} / \mu \mathrm{L}$ at $1 \mathrm{x}$. We verified that PCR efficiency and sensitivity was not different between chicken and sheep target. A threshold cycle $(\mathrm{Ct})$ was determined by the software LightCycler ${ }^{\circ} 4801.5 .0$ based on the amplification curves of the positive individuals; the lower the $\mathrm{Ct}$, the higher the amount of starting template material. Samples with a $\mathrm{Ct}$ greater than 45 were considered to have no identifiable blood meal. The specificity of qPCR products was confirmed by a melting curve analysis (Tm) and control profiles. We used DNA extracts from sheep, chicken, gerbil and rabbit blood as positive controls and sterilised water was used as a negative control. All assays were repeated three times in independent runs.

\section{Reverse line blotting method}

\section{Probe design and peptide nucleic acid clamp}

We used the primers (12S-6F and B12S-9R) and the reverse line blot (RLB) probes for mammals, birds, chicken, sheep and humans as previously designed [25]. In addition, new specific probes were designed for chicken and sheep (Table 1) using 12S rDNA sequences downloaded from GenBank: 96 from birds, 152 from mammals and 12 from lizards. Sequences were aligned using Muscle multi-alignment software [33].

As human DNA can be an important contaminant when using RLB methods and can compete with target DNA [19, 25], we designed a Peptide Nucleic Acid (PNA) clamp [34] to block human 12S mitochondrial gene amplification. The clamp was designed using the alignment of 260 vertebrate sequences of rDNA 12S and targeted 18 nucleotides located on the $\sim 145$ bp $12 \mathrm{~S}$ rDNA amplified fragment. The human-targeted sequence presented a minimum of three mismatches with the other aligned sequences to guarantee specificity of the PNA clamp. The clamp melting temperature (Tm) is $12{ }^{\circ} \mathrm{C}$ higher than the primer melting temperatures [35-37]. A special $30 \mathrm{~s}$ annealing step at $60{ }^{\circ} \mathrm{C}$ allowed the formation of the PNA/DNA complex on human $12 \mathrm{~s}$ rDNA before primer annealing. This blocked the extension of the reverse biotin labelled primer upstream from the hybridisation site of Homo sapiens RLB probe.

\section{PCR amplification}

The amplification of the $\sim 145$ bp fragment of vertebrate $12 \mathrm{~S}$ rDNA was based on a protocol adapted from [25]. Reactions were performed in $50 \mu \mathrm{L}$ reaction mixtures containing $0.5 \mu \mathrm{M}$ of the human PNA Clamp, $0.8 \mu \mathrm{M}$ of $12 \mathrm{~S}-6 \mathrm{~F}$ and B12S-9R primers, $1.25 \mathrm{U}$ of Taq DNA Polymerase with 1x Q-Solution (QIAGEN) and $10 \mu \mathrm{L}$ of DNA extract from ticks. PCRs were performed in a C1000 thermocycler (Bio-Rad, Hercules, California, USA). The PCR program consisted of an initial denaturation step of $3 \mathrm{~min}$ at $94{ }^{\circ} \mathrm{C}$ before the nine first cycles $\left(20 \mathrm{~s}\right.$ at $94{ }^{\circ} \mathrm{C}$ for denaturation; $30 \mathrm{~s}$ at $60{ }^{\circ} \mathrm{C}$ for human PNA clamp annealing; $30 \mathrm{~s}$ at $60{ }^{\circ} \mathrm{C}$, with temperatures dropping by $1{ }^{\circ} \mathrm{C}$ at each cycle until $52{ }^{\circ} \mathrm{C}$ for primer annealing; $30 \mathrm{~s}$ at $72{ }^{\circ} \mathrm{C}$ for extension). These touchdown cycles were followed by 40 cycles at constant temperatures $\left(20 \mathrm{~s}\right.$ at $94{ }^{\circ} \mathrm{C} ; 30 \mathrm{~s}$ at $60{ }^{\circ} \mathrm{C} ; 30 \mathrm{~s}$ at $52{ }^{\circ} \mathrm{C}$; $30 \mathrm{~s}$ at $72{ }^{\circ} \mathrm{C}$ ). Amplified fragments were subsequently analysed using reverse line blotting. 


\section{Reverse line blot hybridisation}

Membranes were prepared with one probe from each target. PCR products were incubated with every probe by reverse line blotting on both membranes as described in [25]. The $H$. sapiens probe was used to verify PNA clamp efficiency. To reveal hybridized biotin labelled PCR products, membranes were incubated for $30 \mathrm{~min}$ at $42{ }^{\circ} \mathrm{C}$ with a $10,000 \times$ diluted Streptavidin IR-Dye 800 (LI-COR, Bad Homburg, Germany). Membranes were then washed twice for $10 \mathrm{~min}$ at $42{ }^{\circ} \mathrm{C}$ in $100 \mathrm{~mL}$ of a 2X SSPE/0.5\% SDS solution and twice for $5 \mathrm{~min}$ at ambient temperature in $100 \mathrm{~mL}$ of a 2X SSPE solution. Then, the IR Dye of Biotin-Streptavidin complex was scanned at $800 \mathrm{~nm}$ with an Odyssey infrared imaging system (LI-COR). Assays on nymphs 2 months postmoult were repeated three times in independent runs. Only one run was performed on the other ticks.

\section{Tick measurements}

As tick size can vary with the quality and quantity of the blood meal [38-40], we measured the length and width of a sub-sample of ticks from each experimental group to provide us with information on the relative quality of different host blood types. As measurements were made on ticks that were not used in host detection, adults of the group "sheep/chicken" were not measured due to low sample sizes (see Additional file 1: Table S1).

All measurements were made using a binocular microscope and the software Leica S.A.S.

\section{Data analysis}

We considered three variables associated with host detection: 1) the detection threshold obtained with the qPCR method, a continuous variable defined by the $\mathrm{Ct}$ cycle at which a positive amplification was found and which reflects the relative quantity of host DNA present; the lower the $\mathrm{Ct}$, the higher the amount of DNA template, 2) the detection rate, that is, the proportion of positive samples found for each experimental group with both RLBH and qPCR techniques and 3) the tick size and how it varied according to host blood type.

We used generalised linear models (GLM) to analyse data. Full models were simplified using a stepwise backward procedure which consisted in sequentially eliminating non-significant terms and interactions (at the 0.05 level) to obtain a minimal model [41, 42]. All statistical analyses were carried out using the lme4 package implemented in the R v3.0.1 statistical software (R Foundation for Statistical Computing, Vienna, Austria).

\section{Detection threshold (Ct)}

We used all positive ticks obtained with the qPCR method to analyse the detection threshold for each experimental group. As these data did not follow a normal distribution, we applied a boxcox transformation $(\gamma=-7)$ to obtain normality [41]. We used "host type", "time post-moult" and "tick life stage" as fixed explanatory variables and determined their significance using a $\chi^{2}$ test.

\section{Detection rate}

Overall detection rate, corresponding to the sensitivity of the method, was measured for each detection technique. Detection rates of qPCR and RLBH techniques (for one run only) were compared using Chi-Squared Contingency test. In addition, repeatability in detection within and between techniques was calculated based on results from individual tick extracts.

Due to differences in the number of blood meals and blood meal size, we analysed ticks from Step 1 (nymphs) and Step 2 (adults) separately (Fig. 1). Within Step 2, we separated adult ticks originated from larvae and nymphs fed on the same host type (Group 1) from those issued from larvae and nymphs fed on different hosts (Group 2). As adult ticks were only analysed once with the RLBH method, we used only the data obtained from the first run of the qPCR assays for comparing the detection rates of the two methods. In the GLM, "tick" was included as a random nested factor and we considered a binomial distribution for the response variable. In nymphs and in Group 1 adults, "method", "host type" and "time post-moult" were used as explanatory variables for host detection rate. In Group 2, "method", "host type", "blood meal life stage" (larval or nymphal) and "time post-moult" were used as explanatory variables for host detection rate. The significance of these explanatory variables was inferred from likelihood ratio tests (LRT).

\section{Tick size}

As for detection rate analyses, we analysed ticks from Step 1 (nymphs) and Step 2 (adults) separately (Fig. 1). We used "host type" and "blood meal life stage" (only for adults) as explanatory variables and determined their significance using $\mathrm{F}$ tests.

\section{Results}

\section{Detection threshold}

No differences were observed in the detection threshold at 2 months and 8 months post-moult $\left(X^{2}{ }_{1}=3.13 \mathrm{e}-25\right.$, $p=0.41)$ nor between nymphs and adults $\left(\mathrm{X}_{1}^{2}=1.28 \mathrm{e}-\right.$ $25, p=0.6)$. Only the origin of the blood meal had a significant effect on the detection threshold $\left(x_{1}^{2}=3.89 \mathrm{e}-24\right.$, $p=0.004$ ) (Additional file 1: Table S2); the detection threshold was lower in ticks when fed on sheep-blood compared to those fed on chicken-blood (sheep: $\mathrm{Ct}=35.33 \pm 1.71$, chicken: $\mathrm{Ct}=37.28 \pm 3.43$ ) (Fig. 2). These results suggest that, in contrast to predictions, more template DNA was 


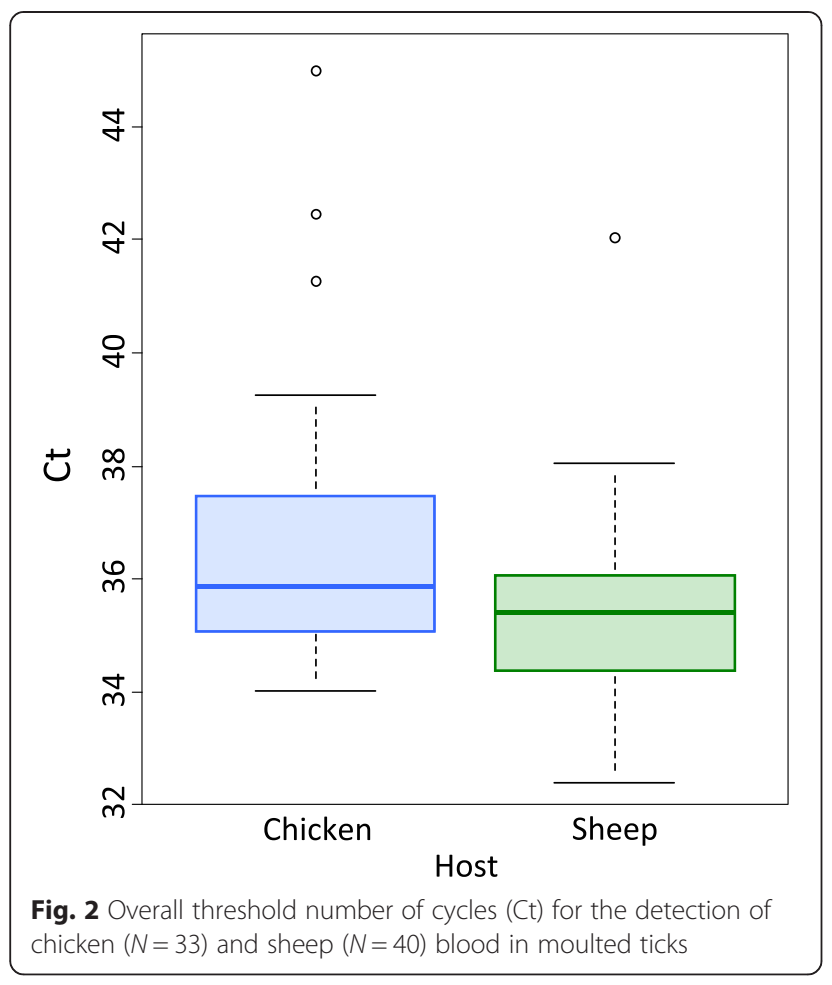

Fig. 2 Overall threshold number of cycles $(\mathrm{Ct})$ for the detection of chicken $(N=33)$ and sheep $(N=40)$ blood in moulted ticks present in sheep-fed ticks post-moult than in bird-fed ticks and that this remnant DNA remained stable over at least an 8-month period.

\section{Detection rate}

We achieved an overall detection rate of $20 \%$ for nymphs and $12 \%$ for adults with qPCR and $22 \%$ for nymphs and $15 \%$ for adults in RLBH. Although sensitivity was significantly higher for the RLBH method $\left(\chi^{2}=4.03, p=0.04\right)$, the repeatability between techniques was reasonably high. Indeed, repeatability was lower among runs within techniques, $77.6 \%$ for $\mathrm{qPCR}$ and $73.4 \%$ for RLBH than between techniques ( $82.5 \%)$.

The detection rate in nymphal ticks was strongly dependant on time post-moult $\left(\chi_{1}^{2}=15.88, p<0.0001\right)$, decreasing over the 6 month interval, but neither host type $\left(\chi_{1}^{2}=0.31\right.$, $p=0.58)$, nor detection method $\left(\chi_{1}^{2}=0.10, p=0.75\right)$ had significant effects (Fig. 3a, Additional file 1: Table S2).

In Group 1 adults (in which larval and nymphal stages fed on the same host type), there was a significant interaction between host type and time post-moult $\left(X^{2}=4.48, p=0.03\right)$; detection rate increased in sheepfed ticks whereas it decreased in chicken-fed ticks. There was also a difference between qPCR and RLBH detection rates at this life stage $\left(\chi_{1}^{2}=10.2, p=0.001\right)$, where rates were higher using the RLBH method (Fig. 3b, Additional file 1: Table S2).

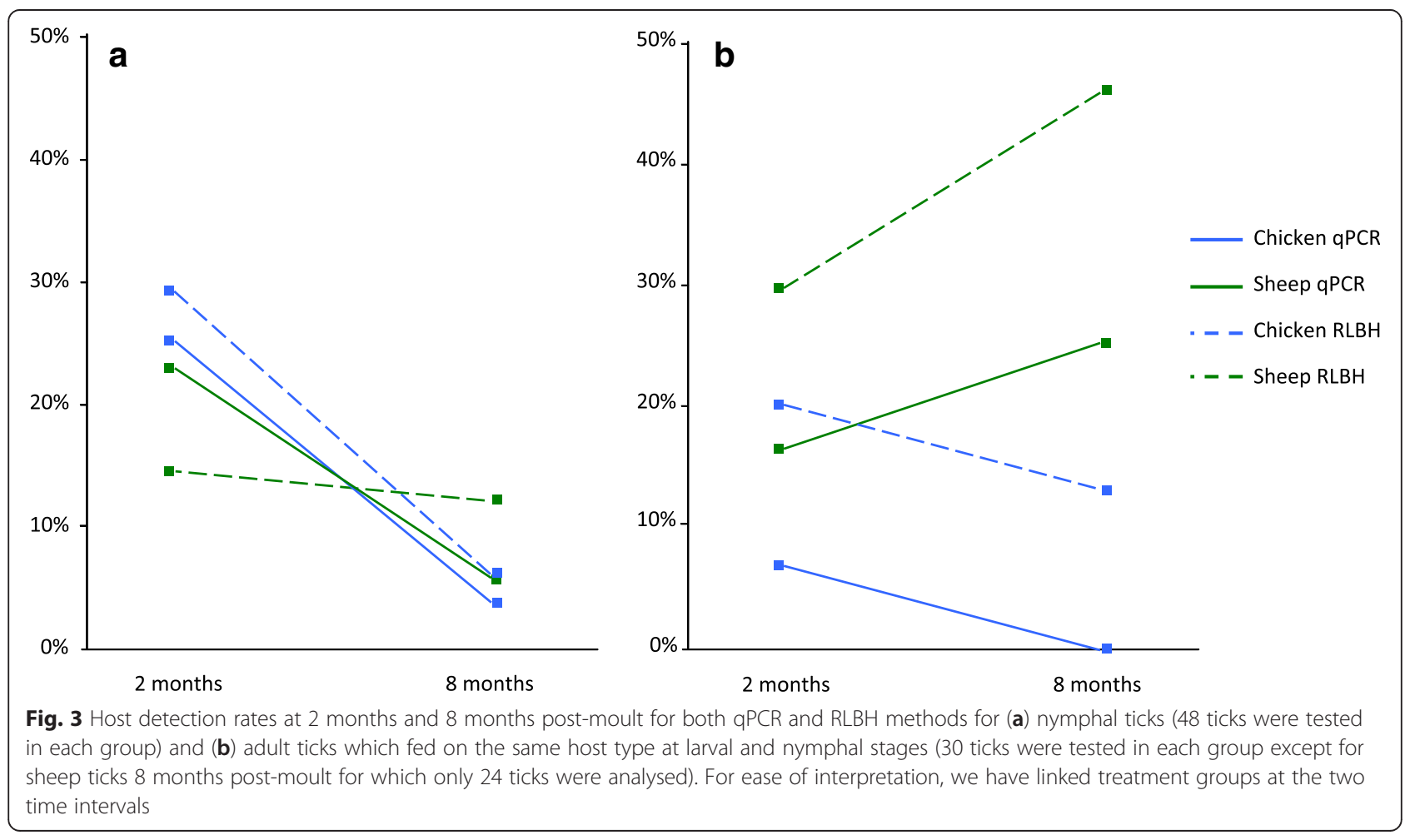


In Group 2 adults (in which larval and nymphal ticks fed on different host types), there was a significant interaction between time post-moult and stage $\left(\mathrm{X}_{1}^{2}=\right.$ 3.94, $p=0.04)$ and between time-post-moult and host type $\left(\chi_{1}^{2}=3.94, p=0.04\right)$ (Table 2 , Additional file 1: Table S2). However, these results should be taken with caution considering the overall low number of successful detections (Table 2).

\section{Tick size}

As the length and width of ticks were strongly correlated (Pearson's correlation; $r=0.98, p<0.0001$ ), we used only length to compare tick size post-moult. In unfed nymphs, size was only influenced by host type used for the larval blood meal $\left(\mathrm{F}_{87,1}=10.1, p=0.002\right)$ (Additional file 1: Table S2); sheep blood-engorged ticks were larger than chicken blood-engorged ticks (chicken ticks: length $=1.09 \pm 0.07$, width $=0.706 \pm 0.05$; sheep ticks: length $=1.13 \pm 0.06$, width $=0.783 \pm 0.05$ ). However, this difference was not evident in adults $\left(\mathrm{F}_{133,2}=1.38\right.$, $p=0.25$ ) (Additional file 1: Table S2).

\section{Discussion}

Numerous studies on vector feeding behaviour have been carried out to better understand vector ecology and to identify potential vertebrate reservoirs of vectorborne pathogens (e.g., [8, 11, 27, 43-47]). Ticks are unique among blood-sucking arthropods as their blood meal typically occurs several months before capture and is largely digested when detection is performed. This trace amount of host DNA, combined with a large host spectrum, makes host identification particularly challenging for certain tick species. In this context, the aim of the present study was to investigate the potential biases associated with indirect host identification methods used for ticks and whether these biases require explicit consideration when making inferences about tick ecology and pathogen transmission cycles. Our results suggest that several factors may indeed affect our image of host use and that these biases are present across molecular techniques (here, qPCR and RLBH).

Table 2 Host detection rate (\%) in adult ticks per method, life stage at which blood meal was taken on each host type and time post-moult

\begin{tabular}{llllll}
\hline Time post-moult & \multicolumn{2}{c}{ qPCR } & \multicolumn{2}{c}{ RLBH } & N \\
\hline \multirow{3}{*}{ 2 months } & Larvae & Nymph & Larvae & Nymph & \\
& 10.00 & $\mathbf{5 . 0 0}$ & 5.00 & $\mathbf{1 0 . 0 0}$ & 20 \\
8 months & $\mathbf{3 . 3 3}$ & 3.33 & $\mathbf{1 6 . 6 7}$ & 3.33 & 30 \\
& 0 & $\mathbf{9 . 0 9}$ & 9.09 & $\mathbf{0}$ & 11 \\
& $\mathbf{0}$ & 20.00 & $\mathbf{4 . 0 0}$ & 12.00 & 25 \\
\hline
\end{tabular}

$\mathrm{N}$ refers to the number of ticks tested. Bold numbers indicate ticks fed on chicken blood and unbold numbers ticks fed on sheep blood (See Fig. 1 for details)
Molecular host detection methods in questing ticks have a general success rate of approximately 50\% $[18,19,25-27,47]$. In our study, overall detection rates were lower than in field-collected ticks, varying between 12 and $20 \%$ and 15 and $22 \%$ for qPCR and RLBH methods respectively. This low sensitivity could be due to the fact that ticks were engorged using an artificial feeding system. In addition to abiotic conditions that change in the laboratory, ticks may show host specificity [48-51] or preferences for particular physical and physiological properties of the host that favour feeding under natural conditions. Indeed, attempts to rear different tick species under laboratory conditions have frequently met with limited success $[29,30,51,52]$. The artificial feeding system we used may also have reduced host detection in another way. In our experiment, the skin used in the feeding apparatus came from a different host type (gerbil or rabbit) than the blood. If remnant host DNA in ticks comes from a mix of digested tissues, skin, white blood and red blood cells rather than from blood only, the low detection rates found in our study might be expected. Indeed, controls during host detection assays showed that both gerbil and rabbit DNA was highly detectable in ticks (results not shown). Despite these potential limitations, the parameters we measured in our study (detection threshold, detection rate and tick size) were obtained under the same artificial feeding conditions, such that comparisons between techniques, hosts, life stages and time are valid, even if overall detection is lower than might be expected under natural conditions.

Detection thresholds differed significantly among host types, but not in the predicted direction. Among positive individuals, amplifications started earlier in sheep-fed ticks compared to chicken-fed ticks suggesting a higher quantity of host DNA when ticks fed on sheep during the previous blood meal. Likewise, sheep blood tended to have higher detection rates than chicken blood, although the difference was not significant. There are several alternative explanations for these unexpected results. Here, nymphs that fed on sheep blood as larvae were generally larger than nymphs that fed on chicken blood. This could suggest that a greater amount of sheep blood (and therefore sheep DNA) was imbibed, on average, compared to chicken-fed ticks during engorgement. However, a recent study using the same basic protocol found that post-engorgement weights are similar for $I$. ricinus ticks that have fed on avian and mammalian blood sources [30]. We know from previous work that host blood quality may influence the size of the vector [51, 53-55] but also the success of DNA amplifications $[56,57]$. The variation we observed could thus be due to differences in host blood characteristics or to host immune responses which reduce blood meal quality [58, 59]; this latter explanation could be particularly 
important within the framework of the present study because fresh chicken blood came directly from living animals rather than via a pharmaceutical company, and therefore may have contained active immune components that were no longer present in the sheep blood. Differences in host quality could also be linked to host specificity in the vector population; the vector being locally adapted to exploit a preferred host $[48,49,51,57,60]$. In our case, the laboratory-reared ticks typically feed on mammalian food sources and may therefore be better adapted to exploit these hosts. Finally, both detection techniques used here rely on the amplification of host DNA in the tick DNA extract. During haemoglobin digestion there is a concentration of residual heme molecules [61] that can act as a PCR inhibitor [20-22]. DNA amplification could therefore vary among host types due to differences in the presence of these inhibitors. Although, we cannot differentiate among these alternative explanations with the present data, our results demonstrate that host type can significantly modify host detection parameters.

Detection rates were lower in adult ticks compared to nymphal ticks. This was surprising, as we expected that the larger blood meal taken in the nymphal life stage would increase detection probability in questing adult ticks. However, given the relative size difference between nymphal and adult life stages, and the difference in the physiological demands of nymphal and adult moults, it may be that the relative amount of host remnant DNA has nothing to do with blood meal size per se. In accordance with our results, Scott et al. (2012) also report a slightly higher detection rate in Amblyomma americanum nymphs compared to adults, without discussing this in more detail [19]. In a few cases, we were able to detect blood remnants from both larval and nymphal blood meals in the same unengorged adult tick. This observation supports previous findings of mixed blood meals in wild adult ticks, results that are frequently (and potentially erroneously) attributed to contaminations $[8,19,25,26]$.

In ticks, DNA-based detection of vertebrate blood meal is possible over long periods of time. In our study, the detection rate was globally higher two months postmoult than eight months post-moult, as expected from previous work [12, 18]. A decline in detection over time has also been found in other hematophagous vectors, but over much shorter time scales [62-64]. However, in adult ticks, sheep detection rates actually increased eight months post-moult, suggesting that previous observations could be host-dependant. Indeed, Woods et al. (2009) have shown that, in fleas, the decrease in detection over time varies among host species [46]. MoránCadenas et al. (2007) and Pichon et al. (2003) found seasonal variation in host blood meal detection success, but could not differentiate between temporal variation in host species exploitation and time since the last blood meal $[26,27]$. Temporal changes in host detection therefore require explicit consideration when studying bloodfeeding behaviour in natural populations, because these changes may or may not reflect true changes in host use. Future work aimed at determining the physiological mechanism behind variation in host detection rates is also called for in order to better understand the origin of this variation and to control for it.

Our results highlight some of the problems that can be encountered when using indirect molecular methods to identify the last host used by a vector. As the goal is to amplify degraded DNA in trace quantities, a first major issue can be contamination. This was particularly a problem for the RLBH technique that includes a wide range of host specific probes. We were able to overcome this issue for human DNA, a frequent contaminate in such studies, by using a PNA clamp. This problem is more difficult to control for other vertebrate host species when using field collected tick specimens and requires specific consideration in detection protocols. Second, although there was relatively high repeatability in individual host detections between $\mathrm{qPCR}$ and RLBH methods (82\%), it was somewhat lower among runs for a given technique $(\sim 75 \%)$. Part of this variation may be due to the probability of pipetting host DNA, present in a small quantities compared to tick DNA. Host detection success in field-collected ticks could therefore be greatly improved by performing replicate assays on the same vector DNA extraction; we recommend running triplicate tests. Here, we compared two methods of host detection, but the utilisation of newer techniques, such as NGS, proteomic or isotopic analyses [1,65-69], could prove more efficient. A comparison of these techniques would be useful for optimizing host detection probabilities and reducing detection biases.

\section{Conclusions}

Biases in host identification can lead to erroneous conclusions on vector feeding ecology and local host use and thus can have severe consequences for understanding patterns of pathogen transmission in nature. Our study, based on an artificial laboratory system, demonstrated that different biases can alter our ability to make robust conclusions for ticks from natural populations. Host effects are particularly important to consider in future work, and notably in relation to how vector adaptation may alter our ability to detect host use. For example, as blood quality may depend on how well ticks are adapted to exploit a particular host type (e.g., ability to digest chicken blood in the present study), the use of novel hosts may be more difficult to detect than typical hosts. This issue could be particularly problematic if we want to measure the role of introduced host species on 
tick population dynamics and pathogen transmission. Our conclusions focus specifically on tick vectors, but potential biases also likely occur in other hematophagous vector species. The investigation of these issues in other vector systems is therefore called for and, particularly so in those systems where host feeding can be controlled under laboratory conditions.

\section{Additional file}

Additional file 1: Table S1. Number of ticks measured in each treatment group of the experiment. Table S2. Description of statistical models used to analyse the influence of host type ("host"), time postmoult ("moult"), tick life stage ("stage"), bloodmeal life stage ("bloodmeal") and method as explanatory fixed variable and tick as a random nested factor on detection threshold, detection rate and tick size. $\mathrm{N}$ gives the number of ticks included in each analysis. "Maximal model" gives the complete set of explanatory variables tested (and their interactions) included in the model. "Minimal model" gives the model containing only the significant variables and their interactions. (DOCX $16 \mathrm{~kb}$ )

\section{Competing interests}

The authors declare that they have no competing interests.

\section{Authors' contributions}

EL designed and carried out the GPCR analysis, performed the statistical analysis and drafted the manuscript. KDM, GV and SB conceived and coordinated the study and helped to draft the manuscript. SB and XL designed the artificial feeding system and carried out tick rearing and engorgement. SM and GV designed and carried out the RLBH analysis. VN participated in the design of the GPCR analysis and helped to draft the manuscript. All authors read and approved the final manuscript.

\section{Acknowledgements}

We would like to thank members of the "Tick and Tick-Borne Diseases" working group of the "Réseau Ecologie des Interactions Durables" for useful discussions and Julien Vézilier and Romain Pigeault for their advice on statistical analyses. Data were obtained using the qPCR platform of the University of Montpellier 2 and with the assistance of Philippe Clair. We thank workers from the CRBM (Centre de Recherches Biomédicales) of the Alfort Veterinary School for assistance. EL was supported by a PhD fellowship from the University of Montpellier 1. Partial financial support was provided by the Agence Nationale de la Recherche (programs OSCAR: ANR-11-AGRO0001-04, ESPEVEC: ANR-13-BSV7-0018-01).

\section{Author details}

${ }^{1}$ MIVEGEC (UMR UM2-UM1-CNRS 5290, UR IRD 224), Centre IRD, 911 avenue Agropolis, BP 64501, 34394 Montpellier, Cedex 5, France. ${ }^{2}$ USC INRA Bartonella-tiques, UMR BIPAR ENVA-ANSES, 94706 Maisons-Alfort, France. ${ }^{3}$ Laboratory of Infection and Immunity, Xu Zhou Medical College, 221004 Xu Zhou, P.R. China. ${ }^{4}$ Unité Epidémiologie Animale (UR INRA 346), Centre de recherche INRA de Clermont-Ferrand / Theix, 63122 Saint Genès Champanelle, France.

Received: 23 April 2015 Accepted: 12 August 2015

Published online: 22 August 2015

\section{References}

1. Gomez-Diaz E, Figuerola J. New perspectives in tracing vector-borne interaction networks. Trends Parasitol. 2010;26:470-6.

2. McCoy KD. The population genetic structure of vectors and our understanding of disease epidemiology. Parasite. 2008;15:444-8.

3. Keesing F, Holt RD, Ostfeld RS. Effects of species diversity on disease risk Ecol Lett. 2006;9:485-98.

4. Kilpatrick AM, Daszak P, Jones MJ, Marra PP, Kramer LD. Host heterogeneity dominates West Nile virus transmission. Proc Biol Sci. 2006;273:2327-33.
5. Kent RJ. Molecular methods for arthropod bloodmeal identification and applications to ecological and vector-borne disease studies. Mol Ecol Resour. 2009;9:4-18.

6. Mukabana WR, Takken W, Knols BGJ. Analysis of arthropod bloodmeals using molecular genetic markers. Trends Parasitol. 2002;18:505-9.

7. Alcaide M, Rico C, Ruiz S, Soriguer R, Munoz J, Figuerola J. Disentangling vector-borne transmission networks: a universal DNA barcoding method to identify vertebrate hosts from arthropod bloodmeals. PLoS One. 2009;4.

8. Allan BF, Goessling LS, Storch GA, Thach RE. Blood meal analysis to identify reservoir hosts for Amblyomma americanum ticks. Emerg Infect Dis. 2010;16:433-40.

9. Buitrago R, Depickere S, Bosseno MF, Patzi ES, Waleckx E, Salas R, et al. Combination of cytochrome $b$ heteroduplex-assay and sequencing for identification of triatomine blood meals. Infect Genet Evol. 2012;12:21-7.

10. Graham CB, Black WC, Boegler KA, Montenieri JA, Holmes JL, Gage KL, et al. Combining real-time polymerase chain reaction using SYBR green I detection and sequencing to identify vertebrate bloodmeals in fleas. J Med Entomol. 2012;49:1442-52.

11. Haouas N, Pesson B, Boudabous R, Dedet JP, Babba H, Ravel C. Development of a molecular tool for the identification of leishmania reservoir hosts by blood meal analysis in the insect vectors. Am J Trop Med Hyg. 2007;77:1054-9.

12. Kirstein F, Gray JS. A molecular marker for the identification of the zoonotic reservoirs of Lyme borreliosis by analysis of the blood meal in its European vector Ixodes ricinus. Appl Environ Microbiol. 1996;62:4060-5.

13. Meece JK, Reynolds CE, Stockwell PJ, Jenson TA, Christensen JE, Reed KD. Identification of mosquito bloodmeal source by terminal restriction fragment length polymorphism profile analysis of the cytochrome B gene. J Med Entomol. 2005;42:657-67.

14. Pettersson E, Bensch S, Ander M, Chirico J, Sigvald R, Ignell R. Molecular identification of bloodmeals and species composition in Culicoides biting midges. Med Vet Entomol. 2013;27:104-12

15. Eisen L, Lane RS. Vectors of Borrelia burdorferi sensu lato. In: Gray J, Kahl O, Lane RS, Stanek G, editors. Lyme Borreliosis: biology, epidemiology and control. Wallingford: CAB International; 2002. p. 91-115.

16. Cotté V, Bonnet $\mathrm{S}$, Cote M, Vayssier-Taussat M. Prevalence of five pathogenic agents in questing Ixodes ricinus ticks from Western France. Vector Borne Zoonotic Dis. 2010;10:723-30.

17. Stanek G, Reiter M. The expanding Lyme Borrelia complex-clinical significance of genomic species? Clin Microbiol Infect. 2011;17:487-93.

18. Pichon B, Egan D, Rogers M, Gray J. Detection and identification of pathogens and host DNA in unfed host-seeking Ixodes ricinus $\mathrm{L}$. (Acari: Ixodidae). J Med Entomol. 2003;40:723-31.

19. Scott MC, Harmon JR, Tsao Jl, Jones CJ, Hickling GJ. Reverse line blot probe design and polymerase chain reaction optimization for bloodmeal analysis of ticks from the eastern United States. J Med Entomol. 2012;49:697-709.

20. WA A -S, Radstrom P. Purification and characterization of PCR-inhibitory components in blood cells. J Clin Microbiol. 2001;39:485-93.

21. Abu Al-Soud W, Jonsson $\amalg$, Radstrom P. Identification and characterization of immunoglobulin $\mathrm{G}$ in blood as a major inhibitor of diagnostic PCR. J Clin Microbiol. 2000;38:345-50.

22. Akane A, Matsubara K, Nakamura H, Takahashi S, Kimura K. Identification of the heme compound copurified with deoxyribonucleic-acid (DNA) from bloodstains, a major inhibitor of polymerase chain-reaction (PCR) amplification. J Forensic Sci. 1994;39:362-72.

23. Raikhel AS. The intestine. In: Raikhel AS, Hoogstraal H, editors. An atlas of ixodid tick ultrastructure. Maryland: Entomological Society of America; 1983. p. 59-97.

24. Tarnowski BI, Coons LB. Ultrastructure of the midgut and blood meal digestion in the adult tick dermacentor variabilis. Exp Appl Acarol. 1989;6:263-89.

25. Humair PF, Douet V, Cadenas FM, Schouls LM, Van de Pol I, Gern L. Molecular identification of bloodmeal source in Ixodes ricinus ticks using 125 rDNA as a genetic marker. J Med Entomol. 2007:44:869-80.

26. Morán-Cadenas F, Rais O, Humair PF, Douet V, Moret J, Gern L. Identification of host bloodmeal source and Borrelia burgdorferi sensu lato in fieldcollected Ixodes ricinus ticks in Chaumont (Switzerland). J Med Entomol. 2007:44:1109-17.

27. Pichon B, Rogers M, Egan D, Gray J. Blood-meal analysis for the identification of reservoir hosts of tick-borne pathogens in Ireland. Vector Borne Zoonotic Dis. 2005;5:172-80. 
28. Bonnet S, Jouglin M, Malandrin L, Becker C, Agoulon A, L'Hostis M, et al. Transstadial and transovarial persistence of Babesia divergens DNA in Ixodes ricinus ticks fed on infected blood in a new skin-feeding technique. Parasitology. 2007;134:197-207.

29. Bonnet S, Liu XY. Laboratory artificial infection of hard ticks: a tool for the analysis of tick-borne pathogen transmission. Acarologia. 2012;52:453-64.

30. Liu XY, Cote M, Paul REL, Bonnet SI. Impact of feeding system and infection status of the blood meal on Ixodes ricinus feeding. Ticks Tick Borne Dis. 2014;5:323-8.

31. Hall T. BIOEDIT: a user-friendly biological sequence alignment, editor and analysis program for Windows 95/98/NT. Nucleic Acids Symp Ser. 1999;41:95-8.

32. Untergasser A, Cutcutache I, Koressaar T, Ye J, Faircloth BC, Remm M, et al. Primer3-new capabilities and interfaces. Nucleic Acids Res. 2012;40, e115.

33. Edgar RC. MUSCLE: multiple sequence alignment with high accuracy and high throughput. Nucleic Acids Res. 2004;32:1792-7.

34. Nielsen PE, Egholm M, Berg $\mathrm{RH}$, Buchardt O. Sequence-selective recognition of DNA by strand displacement with a thymine-substituted polyamide. Science. 1991;254:1497-500.

35. Ganesh KN, Nielsen PE. Peptide nucleic acids: analogs and derivatives. Curr Org Chem. 2000;4:931-43.

36. Le Novere N. MELTING, computing the melting temperature of nucleic acid duplex. Bioinformatics. 2001;17:1226-7.

37. SantaLucia J, Allawi HT, Seneviratne A. Improved nearest-neighbor parameters for predicting DNA duplex stability. Biochemistry (Mosc). 1996:35:3555-62.

38. Amin OM, Sonenshi DE. Development of American Dog tick, DermacentorVariabilis, following partial feeding by immatures. Ann Entomol Soc Am. 1970;63:128-33.

39. Koch HG. Development of the lone star tick, Amblyomma-Americanum (acari, ixodidae), from immatures of different engorgement weights. J Kans Entomol Soc. 1986;59:309-13.

40. Sonenshine DE. Biology of ticks, vol. 2. Oxford: Oxford University Press; 1993.

41. Crawley MJ. The R book. John Wiley \& Sons, Ltd: Chichester UK; 2007.

42. Bolker BM. Ecological models and data in R. New Jersey: Princeton University Press; 2008.

43. Kirstein F, Gray JS. Blood meal identification in ticks: a promising tool in ecological research on tick-borne diseases. Zentralblatt Bakteriol-Int J Med Microbiol Virol Parasitol Infect Dis. 1999;289:760-4.

44. Apperson CS, Hassan HK, Harrison BA, Savage HM, Aspen SE, Farajollahi A, et al. Host feeding patterns of established and potential mosquito vectors of West Nile virus in the eastern United States. Vector Borne Zoonotic Dis. 2004:4:71-82.

45. Bosseno MF, Garcia LS, Baunaure F, Gastelum EM, Gutierrez MS, Kasten FL, et al. Short report: Identification in triatomine vectors of feeding sources and Trypanosoma cruzi variants by heteroduplex assay and a multiplex minjexon polymerase chain reaction. Am J Trop Med Hyg. 2006;74:303-5.

46. Woods ME, Montenieri JA, Eisen RJ, Zeidner NS, Borchert JN, Laudisoit A, et al. Identification of flea blood meals using multiplexed real-time polymerase chain reaction targeting mitochondrial gene fragments. Am J Trop Med Hyg. 2009;80:998-1003.

47. Estrada-Pena A, Osacar JJ, Pichon B, Gray JS. Hosts and pathogen detection for immature stages of Ixodes ricinus (Acari : Ixodidae) in North-Central Spain. Exp Appl Acarol. 2005;37:257-68.

48. Dietrich M, Lobato E, Boulinier T, McCoy KD. An experimental test of host specialisation in a ubiquitous polar ectoparasite: a role for adaptation? J Anim Ecol. 2014;83:576-87.

49. Galun R, Sternberg S. Effects of host spectra on feeding-behavior and reproduction of soft ticks (Acari Argasidae). Bull Entomol Res. 1978;68:153-7.

50. McCoy KD, Leger E, Dietrich M. Host specialization in ticks and transmission of tick-borne diseases: a review. Front Cell Infect Microbiol. 2013;3.

51. Willadsen P, Kemp DH, McKenna RV. Bloodmeal ingestion and utilization as a component of host specificity in the tick, Boophilus-Microplus. Z Parasitenkd-Parasitol Res. 1984;70:415-20.

52. Loomis EC. Rearing of Boophilus-Microplus (Acarina-Ixodidae) on laboratory rabbit. Ann Entomol Soc Am. 1971;64:598.

53. Brunner JL, Cheney L, Keesing F, Killilea M, Logiudice K, Previtali A, et al. Molting success of Ixodes scapularis varies among individual blood meal hosts and species. J Med Entomol. 2011;48:860-6.

54. Kuramochi K. Survival, ovarian development and bloodmeal size for the horn fly Haematobia irritans irritans reared in vitro. Med Vet Entomol. 2000;14:201-6.
55. Venzal JM, Estrada-Pena A. Larval feeding performance of two Neotropical Ornithodoros ticks (Acari: Argasidae) on reptiles. Exp Appl Acarol. 2006;39:315-20.

56. Gariepy TD, Lindsay R, Ogden N, Gregory TR. Identifying the last supper: utility of the DNA barcode library for bloodmeal identification in ticks. Mol Ecol Resour. 2012;12:646-52.

57. Oshaghi MA, Chavshin AR, Vatandoost H. Analysis of mosquito bloodmeals using RFLP markers. Exp Parasitol. 2006;114:259-64.

58. Bize $P$, Jeanneret $C$, Klopfenstein A, Roulin A. What makes a host profitable? Parasites balance host nutritive resources against immunity. Am Nat. 2008;171:107-18.

59. Harrington LC, Edman JD, Scott TW. Why do female Aedes aegypti (Diptera: Culicidae) feed preferentially and frequently on human blood? J Med Entomol. 2001;38:411-22.

60. Sarfati M, Krasnov BR, Ghazaryan L, Khokhlova IS, Fielden LJ, Degen AA. Energy costs of blood digestion in a host-specific haematophagous parasite. J Exp Biol. 2005;208:2489-96.

61. Sonenshine DE. The midgut. In: Biology of ticks, vol. 1. New York: Oxford University Press; 1991. p. 159-88.

62. Mukabana WR, Takken W, Seda P, Killeen GF, Hawley WA, Knols BGJ. Extent of digestion affects the success of amplifying human DNA from blood meals of Anopheles gambiae (Diptera: Culicidae). Bull Entomol Res. 2002;92:233-9.

63. Oshaghi MA, Chavshin AR, Vatandoost H, Yaaghoobi F, Mohtarami F, Noorjah N. Effects of post-ingestion and physical conditions on PCR amplification of host blood meal DNA in mosquitoes. Exp Parasitol. 2006;112:232-6.

64. Steuber S, Abdel-Rady A, Clausen PH. PCR-RFLP analysis: a promising technique for host species identification of blood meals from tsetse flies (Diptera: Glossinidae). Parasitol Res. 2005;97:247-54.

65. Laskay UA, Breci L, Vilcins IME, Dietrich G, Barbour AG, Piesman J, et al. Survival of host blood proteins in Ixodes scapularis (Acari: Ixodidae) ticks: a time course study. J Med Entomol. 2013;50:1282-90.

66. Önder $O$, Shao WG, Kemps BD, Lam H, Brisson D. Identifying sources of tick blood meals using unidentified tandem mass spectral libraries. Nat Commun. 2013;4.

67. Önder O, Shao WG, Lam H, Brisson D. Tracking the sources of blood meals of parasitic arthropods using shotgun proteomics and unidentified tandem mass spectral libraries. Nat Protoc. 2014;9:842-50.

68. Schmidt O, Dautel H, Newton J, Gray JS. Natural isotope signatures of host blood are replicated in moulted ticks. Ticks Tick Borne Dis. 2011;2:225-7.

69. Wickramasekara S, Bunikis J, Wysocki V, Barbour AG. Identification of residual blood proteins in ticks by mass spectrometry proteomics. Emerg Infect Dis. 2008;14:1273-5.

\section{Submit your next manuscript to BioMed Central and take full advantage of:}

- Convenient online submission

- Thorough peer review

- No space constraints or color figure charges

- Immediate publication on acceptance

- Inclusion in PubMed, CAS, Scopus and Google Scholar

- Research which is freely available for redistribution 